\title{
Imersão em Água Quente no Controle Pós-Colheita da Podridão Branca em Maçãs cv. Fuji ${ }^{1}$
}

\author{
Rosangela Lunardi ${ }^{2}$, Rosa M. V. Sanhueza ${ }^{3}$ \& Renar J. Bender ${ }^{4}$ \\ ${ }^{2}$ Faculdade de Agronomia Eliseu Maciel, Universidade Federal de Pelotas, CEP 96001-970, Pelotas, RS; ${ }^{2}$ Embrapa Uva e Vinho, \\ CEP 95700-000 Bento Gonçalves, RS; ${ }^{4}$ Departamento de Horticultura e Silvicultura, Faculdade de Agronomia, Universidade \\ Federal do Rio Grande do Sul, CEP 91501-970 Porto Alegre, RS, e-mail: rjbe@ ufrgs.br
}

(Aceito para publicação em 20/11/2002)

Autor para correspondência: Renar J. Bender

LUNARDI, R., SANHUEZA, R.M.V. \& BENDER, R.J. Imersão em água quente no controle pós-colheita da podridão branca em maçãs cv. Fuji. Fitopatologia Brasileira 28:431-434. 2003.

\section{RESUMO}

O objetivo do presente trabalho foi determinar o efeito do tratamento com água quente no controle da podridão branca (Botryosphaeria dothidea) em maçãs (Malus domestica) cv. Fuji. Os tratamentos foram combinações de três tempos de imersão em água quente $(1,2$, e 3 min) e três temperaturas da água (47, 49 e $52{ }^{\circ} \mathrm{C}$ ), utilizando frutos inoculados com o patógeno. As maçãs foram armazenadas na temperatura de $0-1{ }^{\circ} \mathrm{C} \mathrm{em}$ atmosfera controlada (AC) de 1,2 a 1,6 kPa de $\mathrm{O}_{2}$ e 0,2 a $0,4 \mathrm{kPa}$ de $\mathrm{CO}_{2}$ e em ar refrigerado (AR). As amostras armazenadas foram avaliadas ao final um, três e cinco meses em AC ou AR mais sete dias em temperatura ambiente. Avaliou-se o diâmetro de lesão e variáveis da qualidade dos frutos. Os tratamentos de imersão em água quente reduziram o tamanho das lesões das maçãs quando o tratamento foi de $47{ }^{\circ} \mathrm{C}$ por 3 min em armazenamento em AC. A armazenagem em $\mathrm{AC}$ manteve melhores as características qualitativas das maçãs. dothidea.

Palavras-chave adicionais: controle físico, Botryosphaeria

\section{ABSTRACT}

Post harvest control of white rot on cv. Fuji apples by hot water heat treatments

The objective of the present study was to evaluate the efficacy of heat treatments on the control of white rot caused by Botryosphaeria dothidea on 'Fuji' apples (Malus domestica). Apples were immersed for either 1, 2 or $3 \mathrm{~min}$ in hot water at 47, 49 or $52{ }^{\circ} \mathrm{C}$. Before the heat treatments, the apples were inoculated with the fungus $B$. dothidea. After the treatments, apples were stored at $0-1{ }^{\circ} \mathrm{C}$ in controlled atmosphere (CA) with $1.2-1.6 \mathrm{kPa} \mathrm{O}$ and $0.2-0.4 \mathrm{kPa} \mathrm{CO}_{2}$ or in refrigerated air storage for one, three or five months. After each storage period, samples were transferred to room temperature for seven days and evaluated for lesion diameter and quality parameters. Hot water heat treatment at $47^{\circ} \mathrm{C}$ for 3 min reduced lesion diameter of Fuji apples under CA storage. The CA storage resulted in better quality apples.
Entre as principais doenças que afetam as maçãs (Malus domestica Borkh) no período de verão e em pós-colheita destaca-se a podridão branca, cujo agente causal é Botryosphaeria dothidea (Moug.: Fr) Ces. \& De Not (Bonetti \& Katsurayama, 1998). O patógeno pode causar perdas muito expressivas, podendo chegar à totalidade dos frutos armazenados (Brown \& Britton, 1986). A infecção nos frutos torna-se visível entre seis e oito semanas antes da colheita (Bonetti \& Katsurayama, 1998). Segundo Kohn \& Hendrix (1983) a infecção se inicia quando os teores de sólidos solúveis totais nos frutos atingem os $10,5{ }^{\circ}$ Brix, mas trabalhos feitos por Parker \& Sutton (1993) mostram que a ocorrência da infecção não está correlacionada com os teores de sólidos solúveis totais nos frutos, pois concluíram que a infecção pode ocorrer em qualquer período após a queda das pétalas, sempre que as condições ambientais se tornem favoráveis ao

$\overline{{ }^{1} \text { Parte da }}$ dissertaçãode Mestrado do primeiro autor. Universidade Federal do Rio Grande do Sul. (2000). Apoio FAPERGS e ABPM. Bolsista do CNPq. desenvolvimento da doença. Esta doença tem uma fase latente e, por isso, frutos infetados, assintomáticos na colheita, podem continuar a desenvolver a podridão sob refrigeração.

O controle químico de podridões de frutos em póscolheita está se tornando difícil devido a restrição de uso destes produtos nesta fase de produção (D'Hallewin et al., 1994). Segundo estes autores, estas restrições têm levado a um aumento no interesse em métodos alternativos ou integrados para controlar as desordens de origem patogênica em produtos armazenados.

O tratamento térmico, principalmente água quente, é um método alternativo que tem sido usado há muitos anos para controlar fungos e infestações de insetos em frutos (Couey, 1989). Burchill (1964) controlou Gloeosporium spp. imergindo as maçãs numa variação de temperatura de 40 a $45^{\circ} \mathrm{C}$ durante 6 min. Edney \& Burchill (1967) apud Barkai-Golan \& Phillips (1991) controlaram Gloeosporium spp. e Penicillium expansum Link em maçãs com imersão por 10 min a $45^{\circ} \mathrm{C}$.

$\mathrm{O}$ vapor quente foi também avaliado para controlar $P$. 
expansum e Botrytis cinerea Pers, \& Fr. Os tratamentos utilizados para o controle destes patógenos contribuíram para a manutenção da qualidade dos frutos, principalmente a firmeza de polpa (Lurie et al., 1998; Conway et al., 1999). Entre estes e vários outros trabalhos na literatura não há referências ao controle de $B$. dothidea com tratamento térmico dos frutos.

Aliado ao tratamento térmico, o armazenamento em atmosfera controlada (AC) é citado por diversos autores como meio de inibir o desenvolvimento de fungos (Colgan \& Johnson, 1998). O efeito em reduzir a incidência de patógenos pode ser atribuído ao retardamento na maturação dos tecidos (Chitarra \& Chitarra, 1990).

Tendo em vista a falta de informações sobre os efeitos de tratamentos térmicos com uso de água quente para o controle da podridão branca das maçãs, objetivou-se determinar a combinação de tempo e temperatura mais adequada para o seu controle em maçãs cv. Fuji, armazenadas em $\mathrm{AC}$ e ar refrigerado (AR).

$\mathrm{O}$ experimento foi conduzido nos laboratórios do Departamento de Horticultura e Silvicultura (DHS) da Faculdade de Agronomia da Universidade Federal do Rio Grande do Sul e na unidade frigorífica da Empresa Mercochem Agro-industrial Ltda., com sede no município de Caxias do Sul, RS. As maçãs da cv. Fuji, utilizadas no presente experimento, foram colhidas de pomares da Empresa nos dias 19 e 25 de maio de 1999, com os seguintes índices de maturação: firmeza de polpa de 71,4 N e 70,4 N; acidez titulável de 1,44 Cmol.1 ${ }^{-1} \mathrm{e}$ 1,75 Cmol.1 ${ }^{-1}$; e sólidos solúveis totais (SST) de 13,0 ${ }^{\circ}$ Brix e 14,0 ${ }^{\circ}$ Brix, respectivamente.

Após a colheita, as maçãs foram colocadas em câmara de ar refrigerado a $0-1{ }^{\circ} \mathrm{C}$. Um dia após as datas de colheita, as maçãs foram selecionadas para tamanho e ausência de defeitos e transportadas para o laboratório.

Em seguida, as maçãs foram inoculadas com um isolado de B. dothidea, obtido da coleção da Embrapa Uva e Vinho (BD Cax.). O método usado constou da colocação, em ferimentos das maçãs, de discos de $4 \mathrm{~mm}$ retirados de colônias desenvolvidas em meio BDA (batata, dextrose, ágar e $100 \mu \mathrm{g} \cdot \mathrm{ml}^{-}$

${ }^{1}$ de estreptomicina). Os ferimentos constaram de lesões superficiais feitos em uma área de $2 \mathrm{~mm}^{2}$ na região equatorial das maçãs. Para proteção usou-se uma fita de polietileno ao redor da referida área. As maçãs permaneceram em sacos plásticos por $40 \mathrm{~h}$ à temperatura de $28^{\circ} \mathrm{C}$, conforme recomendações (Dhingra \& Sinclair, 1995). Em seguida, as maçãs foram submetidas aos tratamentos de imersão em água quente em banho maria.

Foram comparados três tempos de imersão: 1, 2 e 3 min e três temperaturas de água: 47,49 e $52{ }^{\circ} \mathrm{C}$. O tratamento testemunha não foi imerso em água. As temperaturas da água e a três profundidades da polpa, 0,5, 1,5 e 2,5 cm, foram monitoradas com termopares com fios de cobre e constantan conectados a um microvoltímetro. As leituras foram realizadas a cada $10 \mathrm{~s}$ durante o tratamento térmico e mais $4 \mathrm{~min}$ em temperatura ambiente. A partir deste momento, o monitoramento da temperatura da polpa foi feito a cada minuto por mais $26 \mathrm{~min}$.
Após os tratamentos de imersão em água quente, uma parte das maçãs foi armazenada em AR e a outra parte em AC com 1,2 a 1,6 kPa de $\mathrm{O}_{2}$ e 0,2 a $0,4 \mathrm{kPa}$ de $\mathrm{CO}_{2}$, ambos em temperatura de $0-1{ }^{\circ} \mathrm{C}$ e umidade relativa do ar da câmara entre 85 e $90 \%$.

As maçãs foram avaliadas após um, três e cinco meses de armazenamento e mais sete dias de exposição à temperatura ambiente. Os parâmetros avaliados foram: diâmetro da lesão $(\mathrm{mm})$, firmeza de polpa $(\mathrm{N})$, determinada com uso de penetrômetro manual com ponteira Magness-Taylor de $11 \mathrm{~mm}$ de diâmetro, SST ( ${ }^{\circ}$ Brix), determinados com refratômetro de mesa, acidez titulável $\left(\mathrm{Cmol} . \mathrm{l}^{-1}\right)$ pela titulação de $10 \mathrm{ml}$ de suco com $\mathrm{NaOH} 0,1 \mathrm{~N}$ até $\mathrm{pH} 8,1$ e perda de peso (\%).

Tecidos localizados a $0,3,0,5$ e a $1 \mathrm{~cm}$ da epiderme foram transferidos para placas com BDA. Dos frutos pertencentes aos tratamentos de imersão por 3 min a $47^{\circ} \mathrm{C}$ e de 2 e 3 min a 52 ${ }^{\circ} \mathrm{C}$ retirou-se os picnídios formados nas lesões transferindoos para meio de BDA. Nos demais tratamentos não foram constatados a presença de frutificações do patógeno. As placas de Petri com picnídios e tecidos das maçãs foram mantidas durante sete a dez dias a $28{ }^{\circ} \mathrm{C}$, sendo então avaliado o desenvolvimento do mesmo.

$\mathrm{O}$ experimento foi conduzido em delineamento experimental inteiramente casualizado, com três repetições por tratamento. Cada unidade experimental estava composta por quatro frutos no experimento em $\mathrm{AC}$ e cinco frutos no experimento em AR. As médias foram comparadas pelo teste de Duncan e por regressão polinomial com $p<0,05$.

Após um mês de armazenamento em AR não houve diferença estatística entre os diâmetros de lesão das maçãs inoculadas e das maçãs submetidas aos diferentes tratamentos de imersão em água quente.

No entanto, com um mês de armazenagem em AC e com sete dias em temperatura ambiente, houve interação entre tempo de exposição das maçãs ao calor e temperatura da água de imersão (Figuras 1A, 1B). Isso denota que o tratamento térmico manifestou controle da podridão branca já no primeiro mês de armazenamento

Com 2 min de imersão em água quente, tanto na saída da armazenagem quanto após sete dias em temperatura ambiente foi observado um decréscimo no diâmetro da lesão com o aumento da temperatura de tratamento. Com 3 min de imersão em água quente, o diâmetro da lesão aumentou com o aumento da temperatura da água de tratamento em ambas as épocas de avaliação. Com 1 min de imersão, quando as maçãs foram retiradas da câmara de armazenagem, não houve diferença estatística no diâmetro de lesão. No entanto, depois de sete dias em temperatura ambiente, foi observado um decréscimo do diâmetro da lesão com incremento na temperatura da água.

Conway et al. (1999) observaram um decréscimo no tamanho da lesão em maçãs da cv. Gala pré-inoculada com Penicillium expansum, conforme aumentou a duração do tratamento térmico.

No presente experimento, em termos de temperatura da água, tanto na saída da armazenagem, quanto após sete dias em temperatura ambiente, o diâmetro de lesão ajustou-se ao 
Imersão em água quente no controle pós-colheita da podridão...

modelo quadrático, indicando um decréscimo no diâmetro da lesão com o aumento do tempo de imersão. A exceção foi na temperatura de $52{ }^{\circ} \mathrm{C}$ na saída da câmara, quando o diâmetro da lesão aumentou linearmente com o tempo de imersão.

Após três meses de armazenamento não foram observadas diferenças significativas entre diâmetros de lesões tanto em AR como em AC, logo após a retirada das amostras da armazenagem assim como também aos sete dias em temperatura ambiente.

Após cinco meses de armazenamento nas maçãs retiradas de câmaras com AR, determinou-se uma interação entre tempo e temperatura, indicando que, de uma maneira geral, houve um aumento do diâmetro de lesão com a elevação da exposição dos frutos à temperatura elevada, salvo a $1 \mathrm{~min}$ de imersão, em que o diâmetro da lesão decresceu linearmente com a elevação da temperatura (Figura 1C). Com sete dias em temperatura ambiente as lesões aumentaram muito em todos os tratamentos, ocorrendo em algumas parcelas perda total (dados não apresentados).

Conway et al. (1999) observaram que após três e seis meses de armazenamento a $1{ }^{\circ} \mathrm{C}$, o tratamento térmico com uso de vapor quente $\left(38^{\circ} \mathrm{C}\right.$ por quatro dias) controlou o fungo $P$. expansum previamente inoculado, enquanto que aqueles não tratados apresentaram lesões com diâmetros acima de $85 \mathrm{~mm}$.

Na comparação das médias dos tratamentos , observouse que o tratamento que melhor controlou o desenvolvimento do fungo, após um mês de armazenamento em AC, foi a $47^{\circ} \mathrm{C}$ durante 3 min de imersão, com um tamanho médio de lesão de $5 \mathrm{~mm}$. Nos demais períodos de armazenamento, o tamanho médio das lesões ficou em torno de 7,2 $\mathrm{mm}$, independente do tempo e da temperatura de imersão.

Botryosphaeria dothidea se desenvolveu a partir de tecidos retirados das maçãs a 0,3 e $0,5 \mathrm{~cm}$ da epiderme, como também dos picnídios formados na sua superfície. Nos tecidos retirados da área com podridão na profundidade de $1 \mathrm{~cm}$, não foi detectada presença de estruturas viáveis do patógeno. Devido à ausência de inibição de $B$. dothidea pelo tratamento térmico nos tecidos superficiais, é possível que um ou vários mecanismos de resistência induzidos pelo tratamento térmico tenham agido nos frutos obstaculizando o desenvolvimento das lesões da podridão branca. Spotts \& Chen (1987), Couey (1989) e Lurie et al. (1998) comentam que o tratamento térmico induz a formação de mecanismos de resistência contra o desenvolvimento dos fungos. Segundo estes autores, pode haver dois mecanismos envolvidos na inibição do desenvolvimento dos patógenos inoculados, indução de fitoalexinas, metabólitos de ação fungicida ou fungistática, e estímulo às defesas estruturais que limitam o desenvolvimento do patógeno nos tecidos (Kays, 1990).

O monitoramento da temperatura das maçãs durante e após os tratamentos mostrou que a temperatura da polpa permaneceu abaixo da temperatura da água de imersão dos tratamentos. Isto sugere que temperaturas menores no interior dos tecidos são suficientes para induzir mecanismos de defesa.

Acredita-se que as concentrações dos gases da atmosfera controlada não tenham contribuído para o retardamento do desenvolvimento do fungo, devido à concentração de $\mathrm{CO}_{2}(0,2$ a $0,4 \mathrm{kPa})$ ser muito baixa e a de $\mathrm{O}_{2}$ (1,2 a 1,4 kPa) alta, para que houvesse ação fungicida ou fungistática. Sommer et al. (1981) e El-Neshawy et al. (1993) afirmaram que atmosferas com alto $\mathrm{CO}_{2}$ (acima de $5 \mathrm{kPa}$ ) são mais efetivas em controlar o desenvolvimento de fungos que atmosferas em hipoxia. No presente experimento não se utilizou atmosfera com elevada concentração de $\mathrm{CO}_{2}$ devido à sensibilidade das maçãs cv. Fuji ao $\mathrm{CO}_{2}$. A sensibilidade da 'Fuji' à alta concentração de $\mathrm{CO}_{2}$ resulta em degenerescência interna da polpa (Bender, 1991; Brackmann et al., 1995) e compostos fermentativos voláteis (Volz et al., 1998).

Com base nesse estudo, verificou-se que é possível inibir o desenvolvimento de $B$. dothidea por tratamento de calor e que a severidade da doença é reduzida pelo tratamento
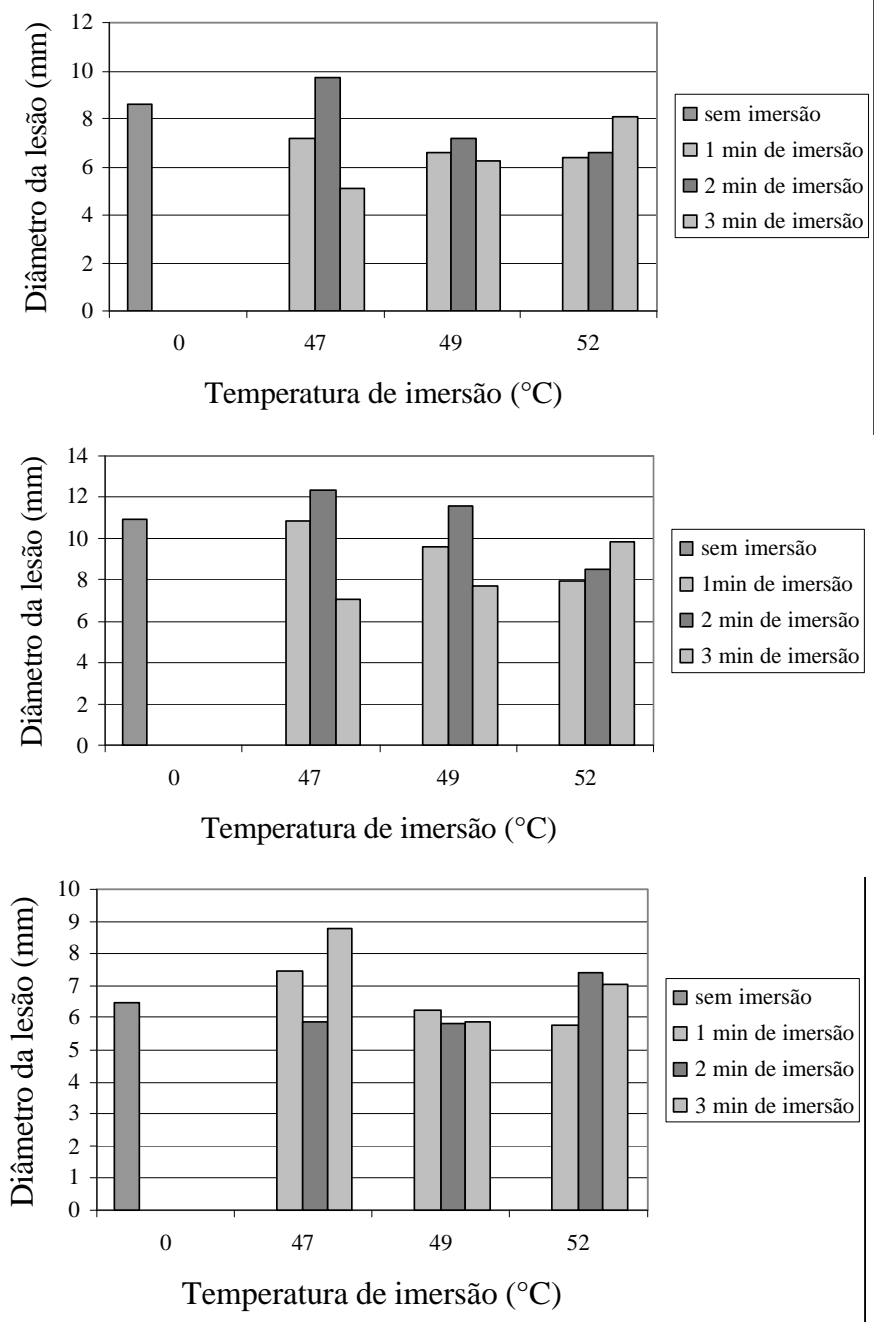

FIG. 1 - Diâmetro da lesão de maçãs (Malus domestica) cv. Fuji inoculadas com Botryosphaeria dothidea, submetidas ao tratamento térmico com imersão em água quente: A) avaliadas após um mês de armazenamento em atmosfera controlada; B) avaliadas após um mês de armazenamento em atmosfera controlada mais sete dias em temperatura ambiente; C) avaliadas após cinco meses em atmosfera refrigerada. Porto Alegre, 1999. 
térmico, sugerindo que o patógeno é afetado pelos mecanismos de defesa do fruto induzidos pelo calor.

Os dados obtidos, caso o método seja utilizado para o controle de infecções latentes, poderá contribuir para a redução de perdas causadas por $B$. dothidea em maçãs cv. Fuji.

\section{REFERÊNCIAS BIBLIOGRÁFICAS}

BARKAI-GOLAN, R. \& PHILLIPS, D.J. Postharvest heat treatment of fresh fruits and vegetables for decay control. Plant Disease 75:10851089. 1991.

BENDER, R.J. Maçã 'Fuji' em atmosfera controlada. Revista Brasileira de Fruticultura 13:301-304. 1991.

BONETI, J.I. da S. \& KATSURAYAMA, Y. Doenças da macieira. São Paulo: BASF S/A, 1998.

BRACKMANN, A., MAZARO, S.M. \& BORTOLUZZI, G. Qualidade da maçã 'Fuji' sob condições de atmosfera controlada. Ciência Rural 25:215-218. 1995.

BROWN, E.A. \& BRITTON, K.O. Botryosphaeria diseases of apple and peach in the Southeastern United States. Plant Disease 70:480484. 1986.

BURCHILL, R.T. Hot water as a possible postharvest control of Gloeosporium rots of stored apples. Plant Pathology 13:106-107. 1964.

CHITARRA, M.I.F. \& CHITARRA, A.B. Pós-colheita de frutos e hortaliças: fisiologia e manuseio. Lavras: ESAL/PAEPE, 1990.

COLGAN, R.J. \& JOHNSON, D.S. The effects of postharvest application of surface sterilizing agents on the incidence of fungal rots in stored apples and pears. Journal of Horticultural Science \& Biotechnology 73:361-366. 1998.

CONWAY, W.S., JANISIEWICZ, W.J., KLEIN, J.D. \& SAMS, C.E. Strategy for combining heat treatment, calcium infiltration, and biological control to reduce postharvest decay of 'Gala' apples. HortScience 34:700-704. 1999.

COUEY, H.M. Heat treatment for control of postharvest diseases and insect pests of fruits. HortScience 24:198-202. 1989.

D'HALLEWIN, G., ARRAS, G. \& CASTIA, T. Reducing decay of Avana mandarin fruit by use of UV, heat and thiabendazole treatments. Acta Horticulturae 368:387-394. 1994.

DHINGRA, O.D. \& SINCLAIR, J.B. Basic Plant Pathology Methods. 2 ed. Boca Raton: Lewis Publishers, 1995. CONFERENCE, 6., 1993, Ithaca. Proceedings. Northeast Regional Agricultural Engineering Service, 1993. V.1, pp.386-392.

KAYS, S. Postharvest Physiology of Perishable Plant Products. New York: Van Nostrand Reinhold, 1990.

KOHN, F.C. \& HENDRIX, F.F. Influence of sugar content and $\mathrm{pH}$ on development of white rot apples. Plant Disease 67:410-412. 1983.

LURIE, S., FALLIK, E., KLEIN, J.D., KOZAR, F. \& KOVACKS, K. Postharvest heat treatment of apples to control San Jose scale (Quadraspidiotus perniciosus, Comstock) and blue mold (Penicillium expansum, Link) and maintain fruit firmness. Journal of the American Society for Horticultural Science 123:110-114. 1998.

PARKER, K.C. \& SUTTON, T.B. Effect of temperature and wetness duration on apple fruit infection and eradicant activity of fungicides against Botryosphaeria dothidea. Plant Disease 77:181185. 1993.

SOMMER, N.F., FORTLAGE, J.R., BUCHANAN, J.R. \& KADER, A.A. Effect of oxygen on carbon monoxide suppression of postharvest pathogens of fruits. Plant Disease 65:347-349. 1981.

SPOTS, R.A. \& CHEN, P.M. Prestorage heat treatments for control of decay of pear fruit. Phytopathology 77:1578-1582. 1987.

VOLZ, R.K., BIASI, W.V. \& MITCHAM, E.J. Fermentative volatile production in relation to carbon dioxide-induced flesh browning in 'Fuji' apple. HortScience 33:1231-1234. 1998. 